ENTREVISTA A JACQUES CHONCHOL

Faride Zeran Chelech 


\section{ENTREVISTA A JACQUES CHONCHOL LA REFORMA AGRARIA EN PRIMERA PERSONA}

¿Cómo se llega a los 91 años lúcido y con la energía para recorrer Chile a propósito de los 50 años de la Reforma Agraria? En el caso de Jacques Chonchol, con convicción. Es lo que refleja el ex vicepresidente de Indap durante el gobierno de Frei Montalva; el ex ministro de Agricultura de Salvador Allende; el cristiano radical y comunitarista discípulo de Maritain y Lebret, y el hombre artífice de la Reforma Agraria a quien un sector del país no duda en calificar de Atila, mientras otro lo convoca en el cincuenta aniversario de uno de los sucesos sociales y económicos más relevantes del siglo XX.

¿Cómo se conmemora un proceso truncado por el golpe de Estado? ¿Desde la celebración o desde la derrota? Para Jean Jacques Chonchol, egresado de Agronomía de la Universidad de Chile, doctor en Viticultura y también en Ciencias Políticas de la Universidad de París, la derrota es una palabra más bien impuesta y que gusta poco de utilizar.

Ex funcionario de FAO y de otros organismos internacionales; ex director del Instituto de Altos Estudios en América Latina durante su exilio de dos décadas en París, y uno de los hombres que por dos años se tuteó con Fidel Castro y Ernesto Che Guevara mientras apoyaba la reforma agraria en la Cuba de 1960, Jacques Chonchol, viudo, un hijo, dos nietos, observa la Casa Central de la Universidad de Chile un día de invierno mientras transcurre esta entrevista y aguarda con su pequeña maleta que alguien lo pase a buscar porque en algún lugar del país lo esperan para hablar de lo que simplemente lo apasiona: la tierra, el campesinado y los cambios políticos y sociales.

Sin duda, un hombre fiel a su siglo.

Faride Zeran Chelech Premio Nacional de Periodismo 


\section{¿Este proceso de transformación fue incluso más allá de lo legado por Allende en sus tres años de gobierno?}

Creo que sí, porque terminó con un sistema social, económico y político que imperaba en el campo prácticamente desde la época de la Colonia. Porque hay que acordarse de que cuando los españoles llegaron aquí había dos instituciones de la colonización: la encomienda y el repartimiento. Repartían grandes superficies de tierras a los soldados que venían con la conquista y al mismo tiempo le entregaban en las encomiendas un cierto número de indios para que trabajaran para ellos. No se llamaban esclavos, pero eran casi esclavos, y se los cedían con la única obligación de enseñarles la fe cristiana. Ese sistema se prolongó durante mucho tiempo y no se modificó en gran parte en la época después de la Independencia. Lo que pasa es que la oligarquía criolla reemplazó a la vieja oligarquía española y el sistema se mantuvo. Ese sistema se caracterizaba por una gran concentración de tierras en manos de un cierto número de privados que tenían todo tipo de poder, especialmente el poder económico, al tener gran cantidad de tierras que se fueron valorizando en el tiempo y que después en el sistema moderno se constituyeron en la mejor garantía que tenían para el sistema bancario, y que tenían otra ventaja: que no se desvalorizaban con la inflación. También tenían poco impuesto, era mínimo porque la oligarquía, que estaba representada por los partidos Conservador y Liberal, tenía mayoría en el Congreso, gracias justamente al poder que tenían sobre la tierra y a que los campesinos tenían un mínimo derecho a voto. Era derecho a voto controlado por ellos, porque en esa época, antes de la reforma electoral, prácticamente lo controlaban. Voto que fabricaban ellos mismos, se los entregaban a los peones, los subían a los camiones y los controlaban, y eso les daba un enorme poder político. Los campesinos eran verdaderos siervos.

\section{Y es precisamente la Reforma Agraria la que termina con la hacienda y el inquilinaje, dos cuestiones claves.}

El inquilinaje es clave, porque es la sucesión de padres a hijos en las mismas haciendas, sin derecho a organizarse sindicalmente, sin remuneraciones. Estas en gran parte se traducían en especies, porque les daban una choza, una casita de mala muerte, un cuarto de tierra, un cuarto de hectárea o de cuadra para que la cultivaran, a veces algún talaje para algunos animales y tenían que trabajar obligatoriamente para la hacienda. 
¿Estamos hablando del mayor proceso de transformación social del siglo XX, incluso mucho más de lo legado por Allende en sus tres años de gobierno?

Lo que pasa es que durante el siglo XX Chile evolucionó bastante en lo urbano, porque hubo sindicatos, un fuerte desarrollo de la clase media, hubo industrialización con el Frente Popular, hubo desarrollo de una clase obrera organizada en sindicatos y un mejoramiento general de las condiciones de vida que se asentó en los últimos 20, 30 años, pero el sistema agrario seguía igual. Y este sistema agrario, además de dar mucho poder político, daba mucho poder económico y social.

Tú señalaste en una ponencia presentada en un debate organizado por LOM en abril último a propósito de los 50 años de la Reforma Agraria, que "con el golpe de Estado cívico militar se detuvo bruscamente el proceso de Reforma Agraria, y es así como el 33\% de la tierra expropiada bajo los gobiernos de Frei y Allende, que alcanzaron a 5.809 predios con casi diez millones de hectáreas, fue devuelto total o parcialmente a sus antiguos propietarios". Y agregas que otro $34 \%$ fue rematado o vendido a capitalistas privados o transferidos a otras instituciones. Cito: "Las tierras restantes fueron asignadas a campesinos, excluyendo y expulsando a todos los dirigentes de las organizaciones sindicales o de la Reforma Agraria. Se estima que se asignaron 45.000 parcelas individuales". ¿Cómo hablamos del hecho más relevante del siglo XX cuando finalmente se trata de un proceso reversible, porque poco o nada de todo eso queda hoy?

No fue reversible en una cosa fundamental: la Reforma Agraria terminó para siempre con el viejo latifundio tradicional, eso no se volvió a reconstituir. Después, con la dictadura, apareció una nueva agricultura capitalista, un mercado libre de tierras. Pero los nuevos empresarios constituyeron una burguesía, inclusive con capital extranjero, pero con una mentalidad distinta a la del latifundista tradicional. Al latifundista tradicional le interesaba el poder político y el poder social, y cultivaba muy mal su tierra y producía muy poco, inclusive el país tenía que importar más alimentos que los que era capaz de exportar. En ese sentido, la Reforma Agraria tuvo un éxito, porque terminó para siempre con este viejo sistema que venía desde la época colonial y que se prolongó con la Independencia y que se terminó con la Reforma Agraria. Ahora, lo que tampoco tuvo éxito es que pretendía consolidar dos cosas: crear una gran agricultura campesina organizada en cooperativas y, para los trabajadores que no tuvieran acceso a la tierra, un gran movimiento sindical, organizando sindicatos poderosos de tipo comunal que les permitieran negociar condiciones de vida mucho más favorables. La contrarreforma terminó con todo 
eso y no solamente volvió una parte de la tierra a los antiguos propietarios, también prohibió la sindicalización campesina, prohibió la Reforma Agraria, prácticamente apareció un nuevo proletariado rural, pero con muy poca fuerza, que existe en algunos sindicatos pero no tiene la misma fuerza de antes. En ese sentido fue un retroceso.

\section{$¿$ No tuvo éxito en esos aspectos porque para consolidarlo fueron solamente seis años, del ' 67 al '73, o porque la contrarreforma fue muy fuerte?}

Ambas cosas. En lo que tampoco hubo un retroceso fue en que se mantuvo la idea de que ciertas características especiales permiten que el valle central de Chile sea una especie de California del hemisferio sur, que está en verano cuando el hemisferio norte está en invierno, lo que permite la especialización en frutas, hortalizas, vinos, etcétera, para exportar al hemisferio norte. Porque en el hemisferio sur Chile no tiene otros competidores que África del Sur y parte de Australia. En ese sentido, tiene una posición geográfica muy favorable y eso siempre se pensó, por ello se venía trabajando con la Corfo y otros organismos para especializar al país en estos productos de exportación. Eso se mantuvo con la contrarreforma agraria, pero ahora en manos de una oligarquía capitalista mucho más progresista en lo técnico y en lo productivo, pero que socialmente sigue explotando a los campesinos de una manera muy fuerte, con un proletariado mal organizado y donde además hay un fenómeno nuevo: la feminización de la fuerza del trabajo. Una buena parte de la fuerza de trabajo son los temporeros y dentro de las temporeros están las temporeras, que trabajan en condiciones muy malas, tienen muy poco nivel de negociación, trabajan doce, trece horas, y el resto del año, cuando no están ocupadas, están cesantes. Pero el legado principal fue la desaparición para siempre del viejo sistema latifundista, eso es indiscutible. Colocar a Chile en una situación de modernización de la agricultura, también es un legado. Qué se perdió: una gran agricultura campesina, organizada en cooperativas, cooperativas de producción, de comercialización, etcétera. Todo eso se acabó. Al mismo tiempo, para aquellos trabajadores de la tierra que no fueran beneficiarios de la Reforma Agraria, se perdió un poderoso sindicalismo que les permitiera negociar condiciones de trabajo más favorables; eso se perdió. Ahora se han perdido otras cosas.

El principal problema de este país es que tiene muy poca tierra agrícola. Nosotros tenemos 75 millones de hectáreas de superficie total y la tierra agrícola son poco menos de cinco millones de hectáreas. El resto son ventisqueros, glaciares, desiertos y con contrastes muy grandes. Inclusive hay una leyenda que cuento a veces, y que es la siguiente:

Dios creó el mundo en siete días, y después de trabajar mucho para crear al mundo se fue a descansar en un rincón del paraíso y de repente San Pedro le tocó la 
puerta y le dijo "señor, señor, despierte” ¿Qué pasa?, preguntó Dios. “Mire, señor, en un rincón del paraíso se nos olvidaron una serie de glaciares, ventisqueros, desiertos, cerros, que no colocamos en ninguna parte y no pueden quedar aquí porque afean el paraíso". Dios, que no quería seguir trabajando, le dijo: "mira, Pedro, busca el último rincón del mundo y lo tiras al otro lado". Y el último rincón del mundo era la Cordillera de Los Andes y entonces San Pedro agarró todo esto y lo tiró al otro lado y así nació la geografía de Chile, que es una de las más complicadas del mundo.

Que se traduce en que de 75 millones de hectáreas, lo que es útil para la agricultura es menos del $10 \%$.

Y eso hoy en día, en parte, se está perdiendo. Se está perdiendo por distintas cosas, entre otras por una nueva moda que ha surgido los últimos veinte, treinta años, la de las parcelas de fines de semana, que justamente se hacen en los alrededores de las grandes ciudades y toman las mejores tierras agrícolas. En ese sentido estamos con un serio riesgo agravado por otro fenómeno nuevo que también se ha producido, que son las plantaciones forestales. Antes no se podía hacer una plantación forestal en tierra agrícola, hoy día puedes hacerla en cualquier parte y todavía con subsidio del Estado. Las grandes empresas forestales fueron muy favorecidas por la dictadura, inclusive con subsidios para forestar, y desde ahí nace también una buena parte del actual problema mapuche.

\section{EL ESPÍRITU DE UNA ÉPOCA}

Sigamos con el balance. Hablemos del espíritu de ese tiempo, de esa época que permitió una transformación tan importante como aquella. ¿Qué Chile era ese? ¿Qué país era el que permitió una transformación de esa envergadura que empieza con la "reforma del macetero" de Alessandri, sigue con la de Eduardo Frei Montalva, cuya ley de 1967 conmemoramos, y que culmina con Allende?

Fueron un conjunto de condiciones internas e internacionales. Los organismos de Naciones Unidas, Cepal, FAO y otros venían alegando, sobre todo la Cepal, que no podía haber desarrollo sin industrialización, y Raúl Prebisch y toda la Cepal ponían todo el acento en la industrialización y en un mercado interno. Y una buena parte del mercado interno de Chile no contaba porque los campesinos vivían en condiciones de subsistencia y no participaban en ninguna parte. Y como una de las condiciones para la industrialización no era solamente invertir en industrias, como 
de cierta manera lo hizo el Frente Popular con la Corfo, sino también crear un mercado, un elemento fundamental para ampliarlo al interior de Chile era mejorar las condiciones sociales del campesino. Eso jugó un rol muy importante. También jugó un rol político muy importante la Revolución Cubana, porque una de las primeras cosas que hizo Fidel Castro fue la reforma agraria en la sierra y después en el resto de Cuba. Eso impactó mucho a América Latina, más cuando llega al gobierno de Estados Unidos, John Kennedy, que tenía otra mentalidad, y planteó que en función de los intereses de Estados Unidos no podían seguir apoyando a los grupos más conservadores, sino a los grupos medios que querían hacer reformas, creando para ello la Alianza para el Progreso.

\section{Esto, para evitar otras Cubas en el continente.}

Así es. Y en una reunión en Punta del Este, donde se estableció la Alianza para el Progreso, se convidó a todos los gobiernos de América Latina y se les dijo por parte de Estados Unidos que si no impulsaban reformas estructurales, entre las cuales estaba la reforma agraria, no habría ayuda ni de los organismos internacionales en que Estados Unidos tenía influencia, ni de ese país. Eso en cuanto a los factores externos. En los internos, en Chile venían creciendo los partidos Socialista y Comunista, y la Democracia Cristiana, todos los cuales planteaban la condición de reforma agraria. Eso hace que la primera ley de Reforma Agraria que tuvimos, "la del macetero", la impulsara el gobierno de Alessandri. Cuando llega al poder, en 1958, no tenía la menor intención de hacer nada, pero se encontró a mitad de camino con todos estos problemas. Entonces se vio forzado a impulsar esta ley, "la del macetero", que no tuvo mucha importancia, pero sicológicamente fue fundamental: por primera vez se planteaba en Chile la Reforma Agraria por un gobierno conservador. Con ello se acababa el sambenito de que la Reforma Agraria era un invento del comunismo internacional para crear el desorden, la anarquía, suprimir la propiedad, etcétera... Todos esos factores externos e internos fueron muy importantes para crear en los años '60 el clima favorable a la Reforma Agraria, y después la llegada al poder primero de Frei y después de Allende, que tenían la voluntad de realizar el proceso, fueron cruciales.

Son tiempos de cambios, pero es además una época de radicalizaciones. Se radicalizan los procesos y las reformas. El propio Jacques Chonchol se va radicalizando con los años, parte en la DC, es figura máxima de Indap con Frei Montalva; se va de la DC, funda el Mapu y termina siendo ministro de Agricultura de Allende. Es un cristiano que se ha radicalizado, son tiempos de radicalización ¿̇o no? 
Hasta tal punto se radicalizó ese periodo que pareció normal que Eduardo Frei, que no era un revolucionario a ultranza sino que un hombre progresista que quería hacer una Reforma Agraria, mandó un proyecto de ley que fue aprobado, que es la ley de Reforma Agraria que estamos celebrando ahora y que establecía ciertas cosas que si lo planteas hoy parece cosa de locos, "de comunistas". Nadie podía tener en este país más de 80 hectáreas de riego básico del Río Maipo o su equivalente; toda operación donde el Estado hiciera inversiones de riego y transformara las tierras en secano, en tierras de riego, era expropiable por el mero hecho. Toda tierra en manos de sociedades o corporaciones era expropiable por el mero hecho de ser sociedad o corporación. La tierra solamente debía estar en manos de personas naturales. Toda el agua se declaró un bien nacional de uso público y no había derecho a propiedad privada ni nada sobre el agua. Se pagaron las tierras al valor fiscal, que era diez veces más bajo que el valor comercial, con un 10\% al contado y en bonos de la Reforma Agraria a 20 o 35 años plazo. Después de pasados tres años de la expropiación de la ley, toda tierra mal trabajada era expropiable por el mero hecho de serlo. Esas condiciones de esa ley, que en esos años fueron absolutamente normales, si tú las planteas en el Chile de hoy, con la mentalidad conservadora que tiene este país, jes una cosa de locos!

Es verdad, pero estamos hablando de un año, el año '67, cuando se hace esta ley, en que estalla la reforma en la Universidad Católica con la toma de la Casa Central y con el lienzo desplegado que dice "chileno, El Mercurio miente", un año antes el mayo francés. Es el año en que la Iglesia juega un papel muy importante y el Cardenal Silva Henríquez juega un rol fundamental. Hablemos de esos ambientes, porque ya no son los marxistas leninistas sino los cristianos de una iglesia radicalizada, que también cumple un papel protagónico. Hablemos de esos años, de ese contexto histórico.

En ese contexto histórico desde luego hay dos cosas muy importantes, la Iglesia ya había jugado un papel importante en años anteriores, cuando los sindicatos campesinos prácticamente eran imposibles, pero podían organizarse en algunos lugares donde los trabajadores más que campesinos eran obreros, como fue en las viñas. Entonces ahí empezó la Iglesia a trabajar la organización sindical, sobre todo en Molina, Talca, y empezaron las primeras huelgas y todo eso fue organizado por la Iglesia Católica, apoyado por la Falange en cierto sentido, y se da la famosa huelga de Molina, que fue una de las primeras huelgas en que veinte, treinta empresas con sus trabajadores se organizaron simultáneamente. Después vino un acuerdo entre el Cardenal Silva Henríquez y Manuel Larraín, Arzobispo de Talca, que creó un organismo que se llamó Improa, para poner en la Reforma 
Agraria todas las tierras de los arzobispados, y es que el Padre Hurtado también había estado en eso. Entonces por un lado tenías a la Iglesia en punta, que además correspondía a lo que venía pasando en otras partes de América Latina, con Helder Cámara, en Brasil, etcétera, y aquí con la Falange que creó la DC y los partidos de izquierda tradicionales comunistas y socialistas, también empujando en el mismo sentido, además del factor externo. Ya no podía decirse más que esto era invento del comunismo internacional, porque los propios Estados Unidos empujaban para eso y todos los organismos internacionales económicos, sociales, importantes que permeaban a América Latina estaban en la misma posición. En esos años se creó un clima muy favorable, mostrando que esto era un paso fundamental desde el punto de vista del desarrollo de los países que permitió que todas esas cosas se hicieran... ¡Hasta que tuvimos el problema de la dictadura! Pero sí. Son tiempos de radicalización.

En ese clima se acerca el fin del gobierno de Frei Montalva, viene el gobierno de Allende, te has ido de la DC y creas el Mapu, llegas a ser precandidato a la presidencia del Mapu en las elecciones en que sale Allende, cuando Pablo Neruda es el precandicato del PC. Hablemos de Jean Jacques Chonchol, "el Robespierre chileno", como te llamaba un sector de la derecha. Un Robespierre cristiano, alejado del marxismo, pero temido y atacado por esa derecha.

Desde que estuve aquí en la Universidad de Chile, en Agronomía, participé y empecé a interesarme en la política, y milité en la juventud falangista, donde tenía compañeros como Andrés Aylwin, Vicente Sota, Julio Silva Solar y otros. En esa época fuimos muy influenciados, y yo particularmente, por dos cosas. Primero por un libro de un filósofo francés que era Jacques Maritain, que se llamaba "El humanismo integral", y por el otro, un cura dominico, Louis Lebret, que creó un movimiento de economía y humanismo, el comunitarismo, que tuvo mucho impacto en todos nosotros. Estábamos influenciados por esas ideas que después tratamos de desarrollar. Yo tuve la experiencia de Cuba, pero me di cuenta en Cuba de que las condiciones eran totalmente distintas. Ese país tenía un campesinado compuesto por descendientes de las Islas Canarias, pero fundamentalmente tenía un proletariado agrícola, ligado a las plantaciones cañeras. Las plantaciones cañeras eran sociedades en manos de capitalista cubanos o de capitalistas norteamericanos, con una mentalidad proletaria; ellos no pedían la tierra, ellos lo que pedían fundamentalmente eran mejores condiciones de trabajo, de vida, y eso Fidel lo entendió muy bien. Al mismo tiempo había una minoría de campesinos que eran descendiente de las Islas Canarias y que querían la tierra. Entonces la Revolución Cubana mantuvo la colectivización de los 
grandes ingenios; se pasó de una colectivización capitalista a una colectivización socialista, pero les dio la propiedad de la tierra a los pequeños agricultores. Esas condiciones no eran aplicables en Chile, teníamos una realidad muy distinta y una de las cosas que aprendí en Cuba y otras experiencia que tuve en México, en Colombia y en otros lugares, es que la reforma agraria no puede ser igual en cualquier parte del mundo. Depende de la situación social, económica, del campesinado.

En Chile teníamos que limitar la propiedad de la tierra porque tenemos muy poca tierra agrícola; había que nacionalizar el agua porque es la única manera de manejarlo regularmente, y creamos en la ley de Reforma Agraria un periodo intermedio, que era el asentamiento.

\section{¿Qué idea estaba tras el asentamiento?}

La idea era la siguiente: "el campesino sabe muy bien cómo cultivar la tierra, pero no tiene idea de cómo entenderse con los bancos, empresas de maquinarias, comerciantes, etcétera. Entonces en la ley de Reforma Agraria se estableció que se expropiaba la tierra, se creaba un periodo intermedio que se llamaba asentamiento y después de ese periodo, que duraba hasta cinco años, se le entregaba la propiedad de la tierra, ya sea en forma familiar, indivisible por herencia para evitar el minifundio, ya sea en forma cooperativa o mixta. Y esa fue la idea fundamental. Después venia la propiedad de la tierra organizada. Al mismo tiempo, a los pequeños agricultores, -ya lo estábamos haciendo desde la época de Indap- los organizábamos en comités, les dábamos crédito, asistencia técnica y después les dábamos una forma de organización cooperativa. En todo eso también influyó una cosa que para mí fue muy importante, que fue Paulo Freire.

\section{Hay un libro de Paulo Freire donde escribes un extenso prólogo.}

Paulo Freire llegó exiliado a Chile y yo lo contraté en Indap, trabajó cuatro años con nosotros y él tenía la idea de alfabetización concientizadora. Empezamos a aplicar los métodos de Paulo Freire, que eran reunir a los campesinos de noche, con una diapositiva, una sábana, se hacía la proyección de una imagen y se discutía en torno a ella. Después, cuando salió la ley sindical, Indap tuvo un rol muy importante en la formación de sindicatos, los campesinos no tenían la menor idea de cómo formar un sindicato comunal, los promotores de Indap se desplazaron por todas partes enseñándoles cómo organizar un sindicato. Todo ese proceso se fue acumulando hasta la llegada de Frei Montalva. Al principio tuvo que aplicar la ley de Alessandri hasta que llegó la nueva ley y expropió bastante y se adelantó mucho, ya que con la ley sindical se organizó un gran sindicalismo. Todo este proceso se prolongó y se 
profundizó con Allende. Lo que fue nuevo con Allende es que esta ley de Reforma Agraria no decía nada sobre los mapuches, pero eso cambia con el gobierno de Allende. Pero si bien con el gobierno de Allende se terminó el gran latifundio, quedaron algunas grandes propiedades que nosotros no expropiamos por razones que nos parecían obvias. Una, porque nos parecieron muy productivas y sobre todo porque se dedicaban a ciertas producciones que eran muy importantes desde el punto de vista del país. Por ejemplo, las grandes viñas. Nosotros no expropiamos las grandes viñas. Cuando se realizó la Unctad le dije a Allende: "mire, Presidente, va a venir gente de todo el mundo, aprovechemos que conozcan los vinos chilenos", y entonces Allende me dijo: "de acuerdo, cómo lo hacemos". "Mire", le respondí, "una vez estuve en Italia en una reunión de Roma, invitado por el Primer Ministro Fanfani y fuimos a Siena, donde había una enoteca en los viejos muros de la ciudad, donde ponían todos los vinos italianos. ¿Por qué no hacemos una enoteca aquí en Chile?", le propuse. Allende accedió y mandamos a unos arquitectos a que recorrieron Europa y dijeron que la única manera era hacer la construcción de una hacienda tipo española e hicimos la enoteca en el Cerro San Cristóbal, que tuvo una falla: la financiaron las grandes viñas, pero no participaron los pequeños viñateros, porque nuestra idea es que fuera una muestra de todos los tipos de vinos de Chile. Pero en fin, ;fue una cosa que se logró! En ese sentido estoy contento de que los vinos chilenos sean apreciados y más conocidos en el mundo, fue una de las cosas que tratamos de hacer. Ahora, lo que más siento es las condiciones en que está el campesinado chileno hoy día y que a este paso nos estamos farreando la poca tierra que hay en este país, que es una cosa fundamental para el futuro.

\section{MAPUCHES Y REFORMA AGRARIA}

\section{Al respecto has escrito que “de los 163 predios con 152 mil hectáreas restituidas a las comunidades mapuches, el $84 \%$ fue devuelto por la dictadura a sus antiguos propietarios". ¿Qué pasó? ¿Y en qué contexto el Presidente Allende le pide en tanto su ministro de Agricultura que se traslade a La Araucanía, que el Ministerio de Agricultura se instale allá?}

Hasta la Independencia, los territorios que tenían los mapuches al sur del Biobío siguieron en manos de los mapuches, ellos no tenían propiedad privada, tenían un sistema de comunidades, tenían ganado, empezaron a penetrar algunos chilenos por la parte de Arauco y adquirieron tierras a los mapuches y se las compraron, pero el resto siguió en manos de los mapuches. Entre 1860 y 1900 y tanto, el Estado le fue quitando las tierras a los mapuches con distintos argumentos: la "pacificación 
de la Araucanía", la ocupación del territorio, la extensión del tamaño de Chile, entre otros argumentos, y esas tierras que les quitaron a los mapuches, una parte la sacaron a remate en predios de 500 o más hectáreas. Así empezaron a traer colonos extranjeros porque había la idea- muy típica en América Latina- de que los indígenas eran atrasados y que la única manera de ser modernos y desarrollados era traer colonos europeos. Pasó en Argentina, en Chile y en otras partes que trajeron colonos, a los que también les dieron una cierta cantidad de tierras. Así, a los mapuches los dejaron reducidos del 100\% del territorio que tenían a un 10\% o menos, y ese poco se lo dieron como compensación en lo que se llama mercedes de tierra, que consistían en una cantidad de tierras que se le daba a un cacique con un determinado número de familia. Pero esas mercedes de tierra después se las fueron quitando los vecinos, con distintos argumentos legales. Los mapuches no sabían leer y escribir, los engañaban y les hacían "corrida de cerco". Entonces había una profunda reivindicación de los mapuches de recuperar no todas las tierras que habían tenido antes, sino aquellas que los estados chilenos le habían dado en las mercedes de tierra. Y eso se plasmó de una manera muy importante ya en el gobierno de Frei Montalva, porque hay que acordarse de que en esa época nació el MIR en la Universidad de Concepción, y los jóvenes del MIR no tenían una base obrera, ni nada, eran jóvenes universitarios. Entonces empezaron a crearse una base social ahí, y uno de los argumentos que levantaron fue "Arauco vuelve a la lucha", empujando la ocupación de esas tierras.

Ocurre que apenas se eligió Allende, en los primeros días de diciembre, lo vinieron a ver representantes de comunidades y le dijeron: "Presidente, queremos que usted venga porque hemos elaborado una nueva ley indígena y queremos entregársela”. Entonces Allende dijo: “de acuerdo, yo voy”. Y fuimos, y hubo una gran manifestación en el estadio de Temuco a mediados de diciembre y ahí le plantearon el nuevo proyecto de ley y el problema de las tierras usurpadas, y Allende me dijo: ¿cómo resolvemos este problema? Porque resulta que la ley de Reforma Agraria no dice nada, no está establecido en ningún artículo que las tierras expropiadas se devuelvan a los mapuches. Allende me dijo: "vamos a trasladar el Ministerio de Agricultura a Temuco y tú te instalas allá con otra sede y expropias tierras, no por la causal de los mapuches, que no existía, sino por otras, fundamentalmente por el tamaño. Así, cada vez que en una expropiación encontramos tierras que habían sido usurpadas, lo primero que hacíamos era devolverlas a los mapuches.

Por esa vía se recuperaron unas 150 mil hectáreas de tierra más o menos, y eso resolvió en parte el problema, pero no completamente, porque esas tierras usurpadas muchas veces no estaban en manos de los usurpadores originales que se habían muerto y tenían herederos. Muchas estaban en manos de propietarios más 
chicos que no eran afectables por la ley de la Reforma Agraria y que no queríamos afectar porque era darle un argumento a la derecha, que decía que el gobierno de Allende quería terminar de colectivizar todas las tierras. Y entonces no pudimos resolverlo y ahí yo tuve una larga conversación con Miguel Enríquez, le expliqué el problema, pero no se resolvió porque la presión social iba de todas maneras.

Y la pregunta que uno se hacía en esa época era si era el MIR el que estaba radicalizando a esos campesinos y mapuches, o era la propia dinámica de esas luchas y reivindicaciones la que empujaba esos radicalismos.

Las dos cosas iban juntas, el MIR se aprovechó de esa situación para crearse una base social, con la consigna de "Arauco vuelve a la lucha", pero la presión venía, los mapuches siempre habían tratado de recuperar esas tierras, durante años y años tuvieron pleitos en los juzgados de indios y gastaban unas fortunas y no recuperaban nada. Entonces había una presión fuerte y también vino la presión política del MIR.

En términos del legado cultural, ¿qué más queda de este proceso? Porque así como uno puede decir que el mayo del ' 68 en el mundo fue una verdadera revolución cultural, en tanto se estaba planteado no solamente el tema de las autonomías y gobernanza de las universidades, sino la liberalización de una sociedad, con la píldora anticonceptiva y otras demandas que nos hablan de un cambio cultural, en el caso de la Reforma Agraria estamos hablando también de cambios culturales fundamentales: terminan la hacienda y el inquilinaje, cambia la relación entre el patrón y su obrero... ¿Qué más? ¿Y qué queda de todo eso?

Lo que fue irreversible fue la desaparición del latifundio, el sistema tradicional que había predominado en la agricultura chilena. Eso desapareció, la hacienda desapareció, y lo que surgió después, con la contrarreforma agraria, es una agricultura capitalista en manos de gente que no tiene la mentalidad de los antiguos latifundistas; gente que quiere producir, hacer negocios, y también se está produciendo una nueva concentración de la tierra, pero no en manos del antiguo latifundio. Desde el punto de vista de la producción esto es más positivo que antes y en ese sentido la Reforma Agraria indirectamente tuvo éxito porque permitió esto, pero social y económicamente es un mundo injusto, porque en gran parte están privados los campesinos de esto, porque en gran parte se están comiendo la poca tierra agrícola que tenemos en este país, y socialmente el campesino está desorganizado, no tiene el poder que tuvo a través de los sindicatos campesinos. 


\section{Aún tienes contacto con parte de esas antiguas estructuras campesinas que conociste hace 50 años. Los ves a algunos de ellos y sabes lo que está pasando hoy con las nuevas generaciones ¿Qué está ocurriendo? ¿Y qué percibes al otro lado? ¿Ves las heridas de las derrotas y de las expropiaciones?}

Con motivo de los 50 años de la Reforma Agraria ha habido una serie de seminarios por todas partes, organizados por distintas universidades. Me ha tocado en los últimos dos meses ir a Valdivia, Temuco, Osorno, a Chillán, ahora tengo que ir a Salamanca, después a Ovalle. En todas partes uno se encuentra con viejos campesinos, los que están todavía vivos, con una gran añoranza de esa época que han trasmitido a los hijos, porque muchas veces son hombres de 90 años, otros ya han muerto y uno se encuentra con una serie de gente que te habla de los recuerdos que les transmitieron sus padres y tienen un recuerdo de esos años. Pero una de las cosas más interesantes y curiosas que ha habido en el último tiempo es lo que ocurre con las mujeres. Las mujeres se han proletarizado de una manera muy importante con esta nueva forma de agricultura, que exige mucho trabajo de temporada, hay mucha temporera. Hay mucha temporera que realiza un trabajo muy precarizado, y mujeres se han organizado en una gran asociación que se llama Anamuri, Asociación Nacional de Mujeres Rurales e Indígenas, que lucha por mejorar las condiciones de vida y de trabajo, y hay otros grupos dispersos de organizaciones campesinas que no tienen el poder y la fuerza que tuvieron en el pasado. Por otro lado se está produciendo un fenómeno nuevo, que es que los jóvenes que no ven muchas oportunidades van saliendo de la agricultura y emigrando a las ciudades, en un fenómeno de "descampecinación". Es decir, hay añoranza del pasado, organización con alguna fuerza de algunos sectores, particularmente de las mujeres, y "descampecinación", en el sentido de dejar la agricultura porque no le ven futuro. Pero me ha llamado la atención en todas estas reuniones a las que he asistido, donde me encuentro con campesinos y campesinos jóvenes, que las añoranzas también se han trasmitido a las nuevas generaciones. Sobre el lado de los que fueron expropiados, siguen despotricando. En las cartas a El Mercurio, cada vez que hablan de Reforma Agraria se lanza toda una serie de cartas de los lectores despotricando que esto fue el acabose, el fin de Chile, etcétera. Pero van quedando pocos. Lo que sí ha surgido es esta nueva agricultura capitalista, que no son los viejos agricultores, es gente que viene de la industria o gente que viene de otras actividades, comerciantes, transportistas, y que hoy día han tomado esta idea de una agricultura muy productiva, de exportación. En ese sentido, indirectamente se ganó desde el punto de vista productivo mucho, pero socialmente el sistema sigue siendo muy injusto. 


\section{LOS DUEÑOS DEL AGUA}

\section{Cuando hablamos de los 50 años de la Reforma Agraria, el tema se analiza desde muchas perspectivas, pero curiosamente se disocia de dos aspectos centrales: el agua y el cambio climático.}

El problema del agua es una cosa absurda, este país tiene un contraste brutal: ¡tienes cero en el Desierto de Atacama y nueve metros de lluvia en el Golfo de Penas! Tenemos contrastes muy grandes. El agua es un elemento fundamental para la agricultura dado que en todo el valle central en el verano llueve muy poco, o sea, si no tuviéramos la cordillera y la acumulación de nieve no podríamos tener una agricultura en este país. Pero el manejo de agua es una cosa crucial y por eso es que en la ley de la Reforma Agraria se estableció que las aguas no podían ser privatizadas, que eran un bien nacional de uso público y el Estado tenía que regularlo. Eso es lo que pasa en casi todos los países del mundo, pero no en Chile, porque la dictadura privatizó el agua, porque hoy día el agua está en manos de compañías mineras, compañías forestales o eléctricas, o de grandes grupos de agricultores. El gobierno está tratando de hacer una modificación del código de agua que no les quita la propiedad, porque el agua se privatizó, pero la regula iy están armando un escándalo terrible! Yo creo que ahí hay un trabajo fundamental para el futuro, hay que volver a este principio de que las aguas son un bien nacional y que no se puede privatizar el agua. Esto, además, agravado con el problema del cambio climático y de las sequías. O sea, en un país en el que el uso del agua es tan difícil, no se puede entregar esto a la propiedad de privados. Hoy día hay grupos de agricultores que pueden tener el agua, venderla separada de la tierra y como un negocio con veinte, treinta años plazo. Eso hay que terminarlo. ¡Es parte de la contrarreforma agraria que resulta fundamentalmente negativa!

\section{¿Cómo Jacques Chonchol participa en las conmemoraciones de los 50 años de la Reforma Agraria en el Chile actual? ¿Cómo enfrenta este hito?}

Lo que pasó entre los años '60 y ‘73 fue un cambio fundamental en la realidad social, económica de este país. Parte de esos logros se han perdido con la contrarrevolución y con la dictadura y con lo que se hizo después. Además se está agravando la pérdida de la escasa tierra útil que tenemos en este país. El mito actual de que Chile va a ser una potencia alimentaria es absurdo. Cuando se compara la cantidad de tierra que tenemos con respecto a Argentina, Brasil, es para morirse de la risa. Inclusive un país como Cuba, que es siete veces más chico que Chile, tiene tanta tierra agrícola como Chile. Lo único positivo que a mi juicio ha quedado es esta nueva mentalidad de una 
agricultura de exportación porque hay que aprovechar las condiciones favorables que tiene Chile, por su ubicación geográfica en el hemisferio sur con respecto del hemisferio norte, eso me parece positivo, eso ya se había pensado antes, pero no se había realizado con la intensidad que se está realizando ahora. Lo otro que preocupa es la gran concentración de la tierra hoy día en manos de sociedades, grupos capitalistas, lo que sea, y al mismo tiempo la desprotección del campesinado que no tiene una legislación social que le permita defenderse en mejores condiciones. Y lo que también resulta grave es esta historia de las compañías forestales, que particularmente en la zona de La Araucanía están creando problemas muy serios.

En ese sentido has apuntado que "Chile ha perdido sus mejores tierras agrícolas, que han sido tomadas por las grandes forestales que han modificado las especies y han generado desplazamiento y empobrecimiento de las poblaciones indígenas, profundizando un conflicto intercultural que persiste hasta ahora".

Fundamentalmente las dos plantaciones que hoy día son el gran negocio, el pino y el eucaliptus. Esto es una mono producción que es riesgosa, lo hemos visto en los últimos incendios en todas partes, Valparaíso, centro, sur, y la flora nativa, que es muy importante en la diversificación del panorama forestal, también se ha venido a menos porque a ninguna de esta compañías le interesa plantar. Además, en La Araucanía tienen un problema muy serio, se chupan toda el agua porque todas estas plantaciones requieren mucha agua y van empobreciendo las comunidades vecinas. Lo que ha entregado la Conadi, que no ha expropiado sino que ha comprado a precio muy caro una cierta cantidad de tierra, una parte de esas tierras no son agrícolas, son forestales, entonces prácticamente esos beneficiarios lo son en condiciones muy limitadas. Hoy existen una serie de problemas de desarrollo, de agricultura y del campesinado que son urgentes de resolver y de enfrentar y no se están enfrentando suficientemente.

Quisiera que nos detuviéramos nuevamente en el tema del conflicto de La Araucanía a propósito de lo que señalabas anteriormente, de cuando Allende te pide que el Ministerio de Agricultura se instale en esa zona para enfrentar la demanda del pueblo mapuche. ¿Cómo ves el conflicto hoy?

Hoy día la mínima parte de esas tierras está en manos de las comunidades a las que se les ha restituido las tierras. Tierras pobres, que se les quita en gran parte el agua, tierras de una de las regiones más pobres de Chile en cuanto a población. Requeriría una política, lo que no es fácil porque hay muchos intereses creados, hay muchos descendientes de los colonos que también defienden sus intereses. Aquí hay un conflicto interclase, interracial. Si vemos los apellidos de muchos de estos 
latifundistas actuales, son todos hijos de extranjeros, entonces defienden también el derecho que ellos tienen a la tierra. Hay un conflicto bastante complejo, pero no te quepa la menor duda de que este país tiene una deuda histórica, fundamental, con la población indígena, y esa deuda tiene que resolverla. Resolverla como otros países que han tenido problemas, dándole autonomía, mayor representación política, acelerando la recuperación de tierras que les han sido usurpadas, porque no están planteando recuperar todas las tierras de antes, y dándoles un apoyo educacional, económico más grande y reconociéndoles cierta autonomía política. Porque hay una nueva generación de mapuches, que ya no son los incultivados de antes, hay muchachos que han ido a la universidad y que tienen títulos universitarios y tienen una mentalidad distinta, y esa generación está presionando por hacerse un espacio. ¡A ellos hay que darles espacio!

Finalmente, más allá del exilio y del retorno, ¿qué se siente concentrar gran parte del odio de esa burguesía expropiada que te sindica como el Atila del campo chileno, o el Robespierre del proceso de la Unidad Popular?

Lo siento como el precio que había que pagar por contribuir a un cambio que me parecía fundamental y por el que luché toda mi vida. Viví veinte años de exilio, tuve suerte, tuve suerte porque tuve un trabajo en un instituto relacionado con América Latina, estuve en contacto con América Latina, en Francia, dirigí muchas tesis porque en el instituto llega mucho latinoamericano. Era el Instituto de Altos Estudios de América Latina, o sea durante los veinte años me seguí empapando de la realidad latinoamericana ampliada no sólo a la cosa de Chile, sino que del resto, y en ese sentido tuve suerte y me siento satisfecho. Pero después que volví a Chile siento que yo con 91 años no tengo ninguna posibilidad de ser ningún actor de nada. Pero por lo menos aspiro a contribuir con algunas ideas que permitan cambiar lo que está ocurriendo hoy día en Chile.

Curioso que pese a los aires de tu tiempo, nunca abrazaras el marxismo. Te mantuviste como un cristiano radical.

Nunca fui y nunca me sentí marxista, ni siquiera leí “El Capital”. Leí "El manifiesto comunista", pero nunca me sentí marxista. Yo estaba influenciado por todas estas ideas, y lo sigo estando, del comunitarismo y de las comunidades de trabajadores y de cristianos por el socialismo. Influenciado no por la Iglesia actual, absolutamente auto marginada de la realidad social de este país. Una Iglesia muy conservadora, tradicionalista. No es la Iglesia que fue en la época de Silva Henríquez y Manuel Larraín, la de la lucha y el combate por la pobreza, y de lo que demostró ser capaz en la época de la dictadura. 